(C) The Author(s), 2020. Published by Cambridge University Press on behalf of the British Institute of International and Comparative Law. This is an Open Access article, distributed under the terms of the Creative Commons Attribution-NonCommercial-NoDerivatives licence (http://creativecommons.org/ licenses/by-nc-nd/4.0/), which permits non-commercial re-use, distribution, and reproduction in any medium, provided the original work is unaltered and is properly cited. The written permission of Cambridge University Press must be obtained for commercial re-use or in order to create a derivative work.

\title{
THE FAILURE OF 'CORE CAPACITIES’ UNDER THE WHO INTERNATIONAL HEALTH REGULATIONS
}

\author{
GiULIO BARTOLINI*
}

\begin{abstract}
Analyses related to the Covid-19 pandemic have mainly addressed measures adopted in response to this event without paying attention to provisions included in the 2005 International Health Regulations which require States to develop predefined core capacities to prevent, control and provide a public health response to the international spread of disease. The legal architecture related to these obligations has, however, various shortcomings and States have largely failed to implement the required measures. Only recently has some practice been developed by the WHO to address these deficiencies, and further action is still required to finally implement this (neglected) cornerstone of the global health system.
\end{abstract}

Keywords: public international law, World Health Organisation, International Health Regulations, disaster risk reduction, due diligence, monitoring mechanisms, Covid-19.

\section{INTRODUCTION}

Current legal analyses of the Covid-19 pandemic have mainly addressed measures which have been adopted by way of response. However, attention should also be paid to prevention and preparedness measures that can significantly mitigate the impact of biological hazards. The 2005 International Health Regulations (IHR) ${ }^{1}$ encapsulate this perspective, particularly through Articles 5 and 13, and Annex 1 which oblige States to develop predefined core capacities in order to be better prepared for health emergencies. However, such obligations, some of which are among the most innovative elements of the 2005 IHR, suffer from various shortcomings, and approximately two-thirds of States parties to this instrument have failed to implement relevant measures due to low or moderate levels of national preparedness. ${ }^{2}$ Furthermore, they are not supported by a systematic monitoring system and have been

* Associate professor of international law, University Roma Tre, Editor-in-Chief of the Yearbook of International Disaster Law, giulio.bartolini@uniroma3.it. Responsible for the Jean Monnet Project 'Disseminating Disaster Law for Europe' 611982-EPP-1-2019-1-IT-EPPJMOPROJECT.

1 WHO, 'Revision of the International Health Regulations' (23 May 2005) WHA58.3.

2 WHO, 'Thematic Paper on the Status of Country Preparedness Capacities' (25 September 2019) <https://apps.who.int/gpmb/assets/thematic_papers/tr-2.pdf>. Assessing different indicators in this area it has been maintained that 'the majority of countries $(66 \%)$ have limited or 
generally neglected by scholars. The recent focus on such issues by the World Health Organization (WHO) and other fora has resulted in the development of some additional initiatives and new instruments by WHO to support their implementation, but ultimately these were too little and too late. This article identifies the content of the relevant legal obligations and relevant practice, advocating some reforms which will enable States to be better able to comply with their obligations.

\section{PREPAREDNESS OBLIGATIONS IN THE IHR: ARTICLES 5 AND 13 AND ANNEX 1}

The 2005 IHR are the final result of a long series of attempts made by States to cope with the international spread of diseases. Based on the experience of the early examples of sanitary conventions adopted since the nineteenth century, the 1945 WHO Constitution granted an extensive law-making power to its plenary body, namely the World Health Assembly. Under Article 21 of the WHO Constitution, this latter body is entrusted with the power 'to adopt regulations concerning: (a) sanitary and quarantine requirements and other procedures designed to prevent the international spread of disease'. Significantly such regulations are able to bind all WHO member states except for those that do not affirmatively opt out of them within a specified time period. ${ }^{3}$

This extensive standard-setting power was originally employed in 1951, when the World Health Assembly adopted the International Sanitary Regulations. These were replaced in 1969 by the first version of the International Health Regulations, ${ }^{4}$ which were themselves slightly modified by a series of amendments in 1973 and 1981 . However, such instruments suffered from a series of shortcomings, particularly the very narrow list of diseases to be notified, ${ }^{5}$ their focus being mainly limited to surveillance activities to be carried out at points of entry and exit, and a heavy reliance on States' notifications for their functioning.

Such inconsistencies, magnified by the health crisis related to SARS (Severe Acute Respiratory Syndrome) in 2002-2003, prompted the World Health Assembly to introduce significant changes in the 2005 IHR, which are currently in force for 196 States, including all WHO Member States, plus the Holy See and Lichtenstein. ${ }^{6}$ In particular, the material scope of application of the 2005 IHR has been substantially modified: the existing exhaustive list of relevant diseases was abandoned in favour of a dynamic and all-encompassing approach aimed at addressing all events amounting to a public health emergency of international concern, regardless of their origins. Additionally, the 2005 IHR have improved the information sharing system, moving from a State monopoly in relation to notifications to permitting the WHO to also take

developed capacity while a minority (34\%) have demonstrated or sustainable capacity' (ibid 14$)$. On failures in the implementation of core capacities see below Sections II and III.

${ }^{3}$ On standard-settings activities in this area see MM Mbengue, 'Public Heath, International Cooperation' in R Wolfrum (ed), Max-Planck Encyclopedia of Public International Law (online edn, Oxford University Press 2010).

4 WHO, 'International Health Regulations' (29 July 1969) WHA22.46.

5 Particularly, since the eradication of smallpox, the 1969 IHR had relevance for only three transmissible diseases: cholera, plague and yellow fever. See DP Fidler, International Law and Infectious Diseases (Oxford University Press 1999) 65-71.

6 WHO, 'States Parties to the International Health Regulations (2005)'<https://www.who.int/ ihr/legal_issues/states_parties/en/>. 
into account 'other reports' (Article 9 IHR), ie non-official sources. Other sections were also modified, such as that concerning recommendations submitted by the WHO to States and Article 43 on the permanent capacity for States to adopt stricter 'additional health measures' than those suggested by the WHO, and their impact on human rights. ${ }^{7}$

Within the framework of this innovative approach, the 2005 IHR have also included a series of obligations related to structural and capacity-building measures which contribute to its overall goal, which is 'to prevent, protect against, control and provide a public health response to the international spread of disease' (Article 2 IHR). In particular, Article 5 IHR provides that '[e]ach State Party shall develop, strengthen and maintain ... the capacity to detect, assess, notify and report events in accordance with these Regulations, as specified in Annex 1'. Article 13 IHR additionally requests States to develop 'the capacity to respond promptly and effectively to public health risks and public health emergencies of international concern as set out in Annex 1', also providing that the 'WHO shall publish, in consultation with Member States, guidelines to support States Parties in the development of public health response capacities.'

As the fulfilment of such obligations is crucial to the overall system of cooperation established by the IHR, deadlines for doing so have also been established. Both provisions require States to act 'as soon as possible but no later than five years from the entry into force' of the IHR (namely 15 June 2007), while permitting requests for an extension of two years in cases of 'justified needs' and, subsequently, a further 2year postponement on the basis of 'exceptional circumstances', both to be granted by the Director-General taking into account the technical advice of the Review Committee based on Article 50 IHR. Such options have been used extensively by States when the deadlines approached: in 2012, 118 States requested an extension, while 38 actually failed to report; in 2014, 81 States asked for a further postponement, while 48 failed to make any communication. ${ }^{8}$ The extensions nonetheless came to an end in 2016: and at that time the WHO Director-General recognised that ' $[\mathrm{p}]$ rogress has been made, but these capacities have not been established in many countries', ${ }^{9}$ but without naming and shaming non-compliant States.

Given their central role in the IHR system, it is crucial to identify the measures which States are expected to adopt on the basis of Articles 5 and 13, as integrated by Annex 1, and the characteristics of the relevant legal obligations. Annex 1, which is subdivided into sections A and B, plays a crucial role as it spells out 'core capacities' required by States. ${ }^{10}$

7 For an extensive survey of the 2005 IHR see DP Fidler, 'From International Sanitary Conventions to Global Health Security: The New International Health Regulations' (2005) 4 CJIL 325. For a recent assessment: GL Burci and M Eccleston-Turner, 'Preparing for the Next Pandemic: The International Health Regulations and World Health Organization during COVID19' (2020) 2 Yearbook of International Disaster Law 261.

${ }^{8}$ WHO, 'Report of the Review Committee on Second Extensions for Establishing National Public Health Capacities and on IHR Implementation' (16 January 2015) EB136/22 Add.1., 2.

9 WHO, 'Annual Report on the Implementation of the International Health Regulations (2005). Report by the Director-General' (18 May 2016) A69/20, para 16.

${ }^{10}$ Based on the reporting system related to the implementation of obligations in this area (see below n 39) the WHO has currently identified 13 'core capacities', namely: C1. Legislation and Financing; C2. IHR Coordination and National IHR Focal Point Functions; C3. Zoonotic events and the human-animal interface; C4. Food safety; C5. Laboratory; C6. Surveillance; C7. Human 
Section B, which is devoted to '[c]ore capacity requirements for designated airports, ports and ground crossings', reflects approaches already present in early sanitary conventions developed since the end of the nineteenth century, and as found in Articles 14-22 of the previous IHR adopted in 1969. The purpose of these core requirements is to ensure that States maintain public health capabilities at points of entry and exit. For instance, Section B imposes obligations 'to provide appropriate space, separate from other travellers, to interview suspect or affected persons' or 'to provide for the assessment and, if required, quarantine of suspect travellers, preferably in facilities away from the point of entry', including the need to arrange for 'the nomination of a coordinator and contact points for relevant point of entry, public health and other agencies and services'. ${ }^{11}$

Section A, however, which is devoted to '[c]ore capacity requirements for surveillance and response', was one of the novelties introduced by the 2005 IHR. ${ }^{12}$ It is based on recommendations included in the 2002 Progress Report on the revision of IHR, aimed at 'achieving a globally agreed minimum standard', for the identification of 'the capacities that a national disease surveillance system will require in order for such emergencies to be detected, evaluated and responded to in a timely manner'. ${ }^{13}$ This section identifies the 'minimum requirements' ${ }^{14}$ required to comply with Articles 5 and 13, setting out a list of public health requirements concerning infrastructure, staffing, decision-making and information capacities which are to be established at the local, intermediate and national level. For instance, at the national level preparedness measures include the need: 'to establish, operate and maintain a national public health emergency response plan'; 'to assess all reports of urgent events within 48 hours', 'to provide support through specialized staff, laboratory analysis of samples... and logistical assistance (e.g. equipment, supplies and transport)'; 'to provide a direct operational link with senior health and other officials to approve rapidly and implement containment and control measures', ${ }^{15}$ etc. However, Annex 1 raises interpretative challenges regarding the content of the measures to be implemented and the characteristics of the relevant obligations.

It should be underlined that ' $[t]$ he surveillance and response capacity obligations in the new IHR are more demanding than those found in the ICESCR [International Covenant on Economic, Social and Cultural Rights]'s right to health', ${ }^{16}$ Article 12(2)(c) of which requires States to progressively adopt 'steps' for the 'prevention, treatment and control of epidemic ... diseases' ${ }^{17}$ Articles 5 and 13 IHR provide for clear deadlines and Annex 1 identifies a series of capacity-building measures which must also be put in place in the same way. In particular, and apart from the possibility of extending the deadlines for implementation, Articles 5 and 13 IHR have been qualified as 'unconditional

Resources; C8. National Health Emergency Framework; C9. Health Service Provision; C10. Risk Communication; C11. Points of Entry; C12. Chemical Events; C13. Radiation Emergencies.

11 IHR (n 1), Annex 1.B, para 2(c) and para 2(d). For the coordinator see ibid, para 2(a).

12 Fidler (n 7) 372-4; S Negri, 'Communicable Disease Control' in GL Burci and B Toebes (eds), Research Handbook on Global Health Law (Edward Elgar 2018) 274.

13 WHO, 'Revision of the International Health Regulations. Progress Report' (2002) 77 Weekly Epidemiological Record 157, 159.

${ }^{15}$ IHR (n 1), Annex 1.A, para 6.

14 IHR (n 1), Annex 1.A, para 2. 16 Fidler (n 7) 373.

17 On this provision see B Saul, D Kinley and J Mowbray, The International Covenant on Economic, Social and Cultural Rights: Commentary, Cases, and Materials (Oxford University Press 2014) 977-1083. 
obligation[s]'18 taking into account how they pay no heed to structural and economic differences between States. Indeed, given the overall goal of preserving 'the integrity of a health security framework that relies on its universality as an essential feature', ${ }^{19}$ such provisions do not envisage there being differential treatment for developing countries, as has occurred in other areas of international law. ${ }^{20}$

Nonetheless, the category of 'obligation générale et complexe "à réalisation progressive" 21 (i.e. general and complex progressive obligations), commonly applied to certain human rights provisions, might provide a theoretical frame of reference in this area too: first, Articles 5 and 13 permitted States to prolong the time frame for the fulfilment of such measures (although subject to fixed deadlines); and, secondly this category also implies the possibility of identifying a series of more specific measures related to obligations of a different nature.

Several required measures, in this case as set out in Annex 1, may be understood as obligations of result, ${ }^{22}$ implying the fulfilment of a series of specific goals within the prescribed period, such as the development of a national public health emergency response plan, laboratories, structures to be established at points of potential disease entry and exit or the appointment of coordinators and contact points in such venues. Annex 1 therefore set out a series of capacity-building measures which require States to develop the 'specific institutional capacity to be able to fulfil the requirements of due diligence', ${ }^{23}$ when fulfilling their duties under Articles 5 and 13 IHR 'to detect, assess, notify and report events' and 'to respond promptly and effectively' to health emergencies. Other measures in Annex 1 reflect a due diligence/obligation of conduct approach, for example regarding guaranteeing the capacity to 'determine rapidly the control measures required to prevent domestic and international spread'. In this latter case States must act in a reasonably cautious and diligent manner, taking the precautionary measures necessary to avoid this negative outcome, without, however, being obliged to ensure such a result, which is inevitably dependent upon highly uncertain factors. ${ }^{24}$

However, even if Annex 1 broadly identifies areas of intervention and potential measures, it lacks quantitative and qualitative precision and fails to set out sub-sets of measures which would fulfil those minimum requirements, further underlining the 'vagueness' 25 which characterises the IHR in this regard. Nonetheless, and similarly

18 Burci and Eccleston-Turner (n 7) 263.

19 GL Burci, 'The USA and the World Health Organization: What Has President Trump Actually Decided and What Are Its Consequences?' EJIL:Talk! (5 June 2020) <https://www. ejiltalk.org/the-usa-and-the-world-health-organization-what-has-president-trump-actually-decidedand-what-are-its-consequences/>.

${ }^{20}$ PA Villarreall, 'Differential Treatment in the International Health Regulations: Towards a Nuanced Perspective' in F Steger et al (eds), Migration and Medicine (Verlag Karl Alber 2020) 157.

21 R Pisillo-Mazzeschi, 'Responsabilité de l'État pour violations des obligations positives relatives aux droits de l'homme' (2009) 333 Recueil des Cours 442. See, furthermore, Saul, Kinley and Mowbray (n 17) 133-72.

22 On such obligations see C Economides, 'Content of the Obligation: Obligations of Means and Obligations of Result' in J Crawford, A Pellet and S Olleson (eds), The Law of International Responsibility (Oxford University Press 2010) 371.

${ }_{23}$ T Koivurova, 'Due Diligence' in Wolfrum (n 3) para 21.

24 On such obligations see R Pisillo-Mazzeschi, 'The Due Diligence Rule and the Nature of the International Responsibility of States' (1992) 35 GYIL 9.

${ }^{25}$ S Goldfarb, 'The Phase-Out and Sunset of Travel Restrictions in the International Health Regulations' (2016) 41 BrookJIntlL 781, 808. 
to other sections of the IHR, ${ }^{26}$ Article 13 permits the WHO to draw up guidelines to assist States in their 'development of public health response capacities'. By doing so, and as recognised by Alvarez, '[t]he revised IHRs deploy, as do other IOs [International Organizations], a blend of hard "binding" instruments (the IHRs themselves) with many softer instruments ... [which] are intended to produce greater consistency in the application of states' legally binding' obligations. ${ }^{27}$ To this end, the WHO Secretariat has produced a series of documents, including: a) the 'Checklist and indicators for monitoring progress in the development of IHR core capacities in States Parties' [the Checklist], originally developed in 2010 and modified in $2013 ;{ }^{28}$ b) models for reports to be submitted by States concerning their implementation of the IHR core capacities; ${ }^{29}$ and c) the 2019 'WHO benchmarks for International Health Regulations capacities' [the WHO benchmarks]. ${ }^{30}$ Additionally, further guidance can also be found in the technical documents produced by the recently launched 'IHR Monitoring and Evaluation Framework', which will be explored in the following section. However, apart from evidencing the pervasive role played by the Secretariats of International Organizations in shaping the measures to be expected of member States, this does not provide a uniform approach.

The Checklist was developed on the basis of 'a consensus of technical expert views drawn globally from WHO Member States, technical institutions, partners, and from within WHO' to detail 'the operational meaning of the capacities required' ${ }^{31}$ by Articles 5 and 13. It provides further content and detailed requirements for the eight core capacities ${ }^{32}$ originally inferred from the IHR and assessed on the basis of three potential levels of performance. For instance, as regards laboratories (Core Capacity 8 ), the Checklist refers to 'staff at national or relevant level trained for the safe shipment of infectious substances according to international standards (ICAO/IATA)' or to there being the possibility for ten 'hazardous specimens per year (to be) referred to national reference laboratories for examination'. ${ }^{33}$ Similarly, the Checklist concerning Core Capacity 5 (Preparedness) calls for the identification of 'available resources, the development of appropriate national stockpiles of resources and the capacity to support operations', or the possibility of guaranteeing 'surge capacity' to respond to health emergencies, ie 'the ability of the health system to expand beyond normal operations to meet a sudden increased demand' for sanitary equipment, staff or patient beds. ${ }^{34}$ These examples illustrate the far-reaching character of potentially relevant measures. Nonetheless, the extent to which compliance with this Checklist

26 For a review of some instruments see A Kamradt-Scott, 'The International Health Regulations (2005). Strengthening Their Effective Implementation and Utilisation' (2019) 16 IOLR 268.

27 JE Alvarez, The Impact of International Organizations on International Law (Brill 2014)

222. $\quad 28$ See WHO/HSE/IHR/2010.1.Rev.1. (2010) and WHO/HSE/GCR/2013.2 (2013).

29 See below (nn 36 and 39).

30 WHO, 'WHO Benchmarks for International Health Regulations (IHR) Capacities' (2019) $<$ https://apps.who.int/iris/handle/10665/311158>.

$31 \mathrm{WHO} / \mathrm{HSE} / \mathrm{GCR} / 2013.2$ (2013) 10 and 14.

32 The Checklist identified eight core capacities, namely: National Legislation, Policy and Financing; Coordination and National Focal Point Communications; Surveillance; Response; Preparedness; Risk Communication; Human Resources; Laboratory. Currently WHO classifies core capacities based on 13 categories (see above n 10).

$33 \mathrm{WHO} / \mathrm{HSE} / \mathrm{GCR} / 2013.2$ (2013) 41.

34 ibid 36. 
can be used to determine whether States are meeting the their minimum requirements is open to doubt, particularly in the light of practice regarding the information required on the implementation of core capacities.

In accordance with Article 54 IHR, monitoring compliance with the IHR is based on a system of mandatory annual reports, ${ }^{35}$ based on models developed by the WHO Secretariat. Their content has, however, moved away from the detailed parameters originally provided in the Checklist. Indeed, the original model (the so-called 'IHR Monitoring Questionnaire') $)^{36}$ developed in 2010 was based on more than 250 questions concerning core capacities, to be self-assessed using a yes/no approach, based largely on the Checklist which was developed at the same time as the Questionnaire, ${ }^{37}$ and thus making an extensive use of qualitative/quantitative benchmarks. ${ }^{38}$

This model was, however, simplified in 2018 with the launch of the so-called 'SPAR (State Party Self-Assessment Annual Reporting Tool)', ${ }^{39}$ as part of reforms recently introduced by WHO which will be scrutinised in the next section. The current model consists of 24 indicators for 13 IHR capacities relevant to Annex 1, ${ }^{40}$ largely referring to formal criteria and using limited benchmarks, on the basis of which States are to conduct a self-assessment against five possible levels of performance, by ticking the appropriate box. For example, indicator C8.3 on 'Emergency Resource Mobilization', covering issues such as staff, stockpiles, logistic and health facilities, attributes the maximum score to States which self-assess that 'resource mapping and mobilization mechanisms are regularly tested and updated'; under indicator C.5 (Laboratory) the maximum score is attributed to States where 'systems are in place to transport specimens to reference laboratories for confirmatory diagnostics from all health facilities'; level three out of five is awarded to States making inventories of 'health sector resources'.

The development of a new model was linked to the need to improve States' compliance regarding reporting obligations and might also be related to persistent and significant gaps in the implementation of core capacities, neither of which encourage the fixing of strict criteria that would further highlighting shortcomings. While the new model has helped increase the number of States submitting reports (127 reports in 2016; 189 in 2018 and 173 in 2019) ${ }^{41}$ it might be argued that its content, which

35 WHO, 'Implementation of the International Health Regulations (2005)' (23 May 2008) WHA61.2.

${ }^{36}$ For its latest version see WHO, 'Questionnaire for Monitoring Progress in the Implementation of IHR Core Capacities in States Parties' (2015) WHO/HSE/GCR/2015_8.

37 For their parallel elaboration see WHO, 'Guidance Document for the State Party SelfAssessment Annual Reporting Tool' (2018) WHO/WHE/CPI/2018.17, 19: 'In 2010, the WHO Secretariat developed the document 'IHR Core Capacity Monitoring Framework: Checklist and Indicators for Monitoring Progress in the Development of IHR Core Capacities in States Parties' and the related IHR Monitoring Questionnaire was proposed to States Parties for reporting annually to the World Health Assembly'.

${ }^{38}$ For instance, the examples pertaining to laboratories and preparedness were addressed in the IHR Monitoring Questionnaire through multiple questions (see questions 8.1.1.12-13 and 5.1.1.510, 5.2.1.6-9).

39 WHO, 'State Party Self-Assessment Annual Reporting Tool' (2018) WHO/WHE/CPI/ 2018.16

${ }^{40}$ For the list of 13 IHR Capacities see above (n 10).

${ }^{41}$ WHO, 'IHR State Parties Self-Assessment Reports Received 2010-2018' < https://extranet. who.int/sph/spar $>$ and for data related to 2019 see $<$ https://extranet.who.int/e-spar $>$. 
largely departs from the detailed approach of the Checklist and of the previous reporting model, fails to contribute to the identification of what is expected in terms of the core capacities.

Nonetheless, a more detailed approach is found in the 2019 WHO Benchmarks, ${ }^{42}$ drafted by the Secretariat to assist States in the development of a voluntary 'National Action Plan for Health Security'. ${ }^{43}$ Such Plans have now been produced by more than 50 States and are intended to set an agenda for addressing shortcomings concerning capacity-building measures required by the IHR and other health issues, such as vaccines or food security. ${ }^{44}$ Sections of the Benchmarks which address core capacities, even if structured in the same way as the current model report and referencing the five potential levels of performance, also include very detailed criteria. $^{45}$

The core capacities system suffers from some shortcomings, in particular regarding clearly identifying the content of measures required and what States are expected to achieve. In particular, and unlike other areas of international law in which subsequent international standards have helped tailor and develop international obligations, ${ }^{46}$ there have been unhelpful changes in the approach to what is required of States within those instruments produced on the basis of Article 13 IHR. This is partly due to the failure of States to implement such measures, which has militated against fixing yet more standardised criteria that would further emphasis their current shortcomings.

Finally, the monitoring system lacks the capacity to help clarify the content of the obligations. Even if the scores submitted by States in their reports are made public, they are not then subject to a form of critical review as is common in other areas of international law, this 'reflecting state party concern with maintaining sovereignty on politically sensitive matters' ${ }^{47}$ No debate regarding reports, on-site visits or direct engagement with States is provided for, and there are no adverse consequences if reports are submitted late, incomplete or are not submitted at all. This lack of subsequent scrutiny does not facilitate reflection on the potential measures and does not permit the provision of more details regarding the thresholds expected to be fulfilled by States. Furthermore, the non-confrontational approach based on

42 See (n 30).

43 WHO, 'NAPHS for ALL - A Country Implementation Guide for NAPHS' (2019) WHO/ WHE/CPI/19.5.

${ }^{44}$ For the first example see J Mghamba et al, 'Developing a Multisectoral National Action Plan for Health Security (NAPHS) to Implement the International Health Regulations (IHR 2005) in Tanzania' (2018) 3 BMJ Global Health 1.

${ }^{45}$ For example, ten pages are devoted to laboratories (indicator C.5), identifying specific measures, standards (such as ISO) and targets (for instance, regarding the percentages of health centres capable of transferring specimens to specialised laboratories).

${ }^{46}$ Regarding the law of the sea see C Redgwell, 'Mind the Gap in GAIRS: The Role of Other Instruments in LOSC Regime Implementation in the Offshore Energy Sector' (2014) 29 International Journal Marine \& Coastal Law 600.

47 A Taylor and R Habibi, 'The Collapse of Global Cooperation under the WHO International Health Regulations at the Outset of COVID-19: Sculpting the Future of Global Health Governance' ASIL Insights (5 June 2020) <https://www.asil.org/insights/volume/24/issue/15/collapse-globalcooperation-under-who-international-health-regulations $>$. 
self-assessments makes it difficult to argue that these reports provide an effective indication of the functionality of core capacities. ${ }^{48}$

\section{CURRENT SHORTCOMINGS AND RECENT PRACTICE BY THE WHO}

Irrespective of the inconsistencies in the normative framework related to the core capacities required by the IHR, it is self-evident that compliance with such standards depends on the public health capacities of the States concerned. Unfortunately, " $[t]$ he IHR lack detailed strategies for capacity building'. ${ }^{49}$ Indeed Article 44 IHR, dealing with collaboration and assistance by States and the WHO, has been described as a 'weak obligation on financial and technical assistance'. ${ }^{50}$ It is also important to remember that nearly 80 per cent of the WHO's budget is voluntary and much of this takes the form of earmarked contributions, ${ }^{51}$ thus 'precluding holistic preparedness efforts and hindering the WHO's ability to provide a global safety net'. ${ }^{52}$ These features suggest there is 'limited international solidarity to support the weakest countries in building capacities', as recognised by the 2015 Report of the IHR Review Committee..$^{53}$

This situation, coupled with the weak monitoring system and failure to prioritise such issues in national agendas, has produced significant gaps in the implementation of capacity-building measures required by the IHR. Based on self-assessments provided by States in 2018 and additional data assessed by the WHO, some two-thirds of States have poor or modest levels of preparedness, with overall scores ranging from levels 1 to 3 out of a possible $5,{ }^{54}$ meaning that they are unprepared for pandemics. Such data, largely based on self-assessments by official sources, should be read alongside authoritative independent analysis, such as the Global Health Security Index which evaluates States' capabilities and preparedness to respond to pandemics. Their most recent report, released in 2019, provided an average country preparedness score of 40.2 per cent with dramatic data related to regions such as Africa and in the Global South. ${ }^{55}$

There has been a growing awareness of this unsatisfactory situation due to: a) the end of the grace period provided by the IHR for the attainment of the goals set; b) reports by the IHR Review Committees on the H1N1 and Ebola outbreaks, which underlined structural deficiencies regarding core capacities as critical factors in worsening health emergencies; ${ }^{56} \mathrm{c}$ ) assessments conducted by the United Nations regarding the

48 LO Gostin and R Katz, 'The International Health Regulations: The Governing Framework for Global Health Security’ (2016) 94 The Milbank Quarterly 264, 278.

49 LO Gostin, Global Health Law (Harvard University Press 2014) 188.

50 Fidler (n 7) 374.

51 K Daugirdas and GL Burci, 'Financing the World Health Organization: What Lessons for Multilateralism?’ (2019) 16 IOLR 299.

52 Global Preparedness Monitoring Board, A World at Risk. Annual Report on Global Preparedness for Health Emergencies (World Health Organization 2019) 33.

53 WHO (n 8) para 17.

54 WHO (n 2).

55 For the 2019 report see <https://www.ghsindex.org/wp-content/uploads/2019/10/2019Global-Health-Security-Index.pdf $>$. See furthermore M Sirleaf, 'Capacity-Building, International Cooperation, and COVID-19’ ASIL Insight (9 July 2020) < https://www.asil.org/insights/volume/ 24/issue/17/capacity-building-international-cooperation-and-covid-19>.

56 WHO, 'Report of the Review Committee on the Functioning of the International Health Regulations (2005) in relation to Pandemic (H1N1) 2009' (5 May 2010) A64/10, 12-13; WHO, 'Report of the Review Committee on the Role of the International Health Regulations (2005) in the Ebola Outbreak and Response' (13 May 2016) A69/21, 18-27. 
inadequate levels of preparedness, carried out by high-level Panels of Experts in the aftermath of the Ebola crisis; ${ }^{57}$ d) negative evaluations provided by authoritative private organizations. ${ }^{58}$

As a result, various informal bodies have been established to help address such concerns, such as the Global Preparedness Monitoring Board in 2018, composed of high-level independent experts and supported by WHO, which acts as its Secretariat. Other initiatives, such as the Global Health Security Agenda (GHSA), ${ }^{59}$ have taken place outside of the WHO framework due to 'frustration with lack of progress on IHR implementation'. ${ }^{60}$ This latter initiative was launched in 2014 under the leadership of the US with the original support of 26 other States (currently 67). This involves private actors as well as certain international organisations, including the WHO and FAO. The aim was to accelerate progresses, raise awareness and improve the capacity of States to comply not only with the IHR but also with other international standards and treaties, such as those provided by the World Organization for Animal Health ${ }^{61}$ or the 1972 Biological Weapons Convention ${ }^{62}$ through a multisectoral approach.

Led by the US Centers for Disease Control and Prevention (CDC), in 2014-15 GHSA developed an evaluation tool to monitor results by States in technical areas, such as laboratory systems, surveillance or zoonotic diseases, based on a series of instruments such as the WHO IHR annual reporting tool ${ }^{63}$ or the CDC's Public Health Preparedness Capabilities. ${ }^{64}$ A series of pilot assessments were carried out in six countries with the WHO participating as an observer, and the WHO was thus able to draw on its experience of the evaluation tool when later developing its own practice. Currently GHSA is focused on fostering cooperation and providing support for strengthening domestic capacities in technical areas relevant to the IHR core capacities. It engages with States, international organisations and private actors in a series of voluntary commitments concerning targets in this area, such as financial or technical support to developing States or adhering to some of the capacity-building initiatives developed by WHO. ${ }^{65}$

57 UNGA, 'Protecting Humanity from Future Health Crises. Report of the High-level Panel on the Global Response to Health Crises' (9 February 2016) UN Doc A/70/723; UNGA 'Report of the Global Health Crises Task Force. Note by the Secretary-General' (22 June 2017).

${ }_{58}$ Commission on Global Health Risk Framework for the Future, The Neglected Dimension of Global Security: A Framework to Counter Infectious Disease Crises (National Academies Press 2016).

${ }^{59}$ On this initiative see BM Meier, 'Examining National Public Health Law to Realize the Global Health Security Agenda’ (2017) 25 Medical Law Review 1.

60 Gostin and Katz (n 48) 265.

61 See in particular references to the Performance of Veterinary Services Pathway. For its most recent version see World Health Organisation, 'OIE Tool for the Evaluation of Performance of Veterinary Services' (2019) <https://www.oie.int/fileadmin/Home/eng/Support_to_ OIE_Members/docs/pdf/2019_PVS_Tool_FINAL.pdf>.

${ }_{2} 2$ Convention on the Prohibition of the Development, Production and Stockpiling of Bacteriological (Biological) and Toxin Weapons and on their Destruction of 10 April 1974, 1015 UNTS 163 .

63 See (n 36).

${ }^{64}$ CDC, Public Health Preparedness Capabilities: National Standards for State and Local Planning (July 2011) < https://www.cdc.gov/cpr/readiness/00_docs/DSLR_capabilities_July.pdf>.

${ }_{65}$ For the 'Commitments to the GHSA 2024 Targets' see < https://ghsagenda.org/wp-content/ uploads/2020/07/commitment-visualization-07222020.pdf>. 
This initiative exemplifies the current need to 'take into account the actions and interactions of a much wider range of institutional actors' 66 in the area of global health law, aside from WHO. However, as regards preparedness for pandemics, this raises the risk of fragmentations and dispersal of resources due to partly overlapping agendas, as well as being exposed to fluctuating political dynamics. The latter was experienced by the GHSA when the US administration reduced its leadership role within the network and its funding, which subsequently decreased globally. ${ }^{67}$

Recent changes within the WHO system have, however, produced some (modest) results. In particular, the 2015 Report of the IHR Review Committee regarding the second extension concluded in its Recommendation No 7 that '[i]mplementation of the IHR should now advance beyond simple "implementation checklists", suggesting that the WHO Secretariat develop 'options to move from exclusive self-evaluation to approaches that combine self-evaluation, peer review and voluntary external evaluations involving a combination of domestic and independent experts' ${ }^{68}$ This suggestion was endorsed in World Health Assembly Resolution 68.5 (2015) and led the Director-General to present, in $2016,{ }^{69}$ some new voluntary technical tools to complement the annual report, finally resulting in the current 'IHR Monitoring and Evaluation Framework', ie a series of tools designed to support States in the implementation of core capacities.

Regarding the only mandatory element of the Framework, the annual reports, the only change involved the development of the new model for reporting, the shortcomings of which have already been considered. Conversely, three new voluntary tools have been developed to facilitate evaluations aimed at identifying the most critical domestic challenges. Two of these can be autonomously managed by States based on WHO guidelines: simulation exercises for public health emergencies (and 128 exercises have been conducted so far) and the Guidance for After Action Reviews (of which 64 have so far been undertaken). ${ }^{70}$

Finally, the Joint External Evaluation (JEE) provides for independent assessments of progress made toward achieving the measures provided for under Annex 1 IHR. The mechanism, based on previous WHO experiences, ${ }^{71}$ benefitted from the early review mechanisms managed by GHSA, mentioned above. In particular, in January 2016 the WHO convened a meeting with GHSA partners and the CDC to finalise its JEE tool, based on this previous instrument and its pilot assessments. This finally permitted the WHO Secretariat to adopt a consolidated JEE tool in February 2016 which was

${ }^{66}$ GL Burci and A Cassels, 'Health' in JK Cogan, I Hurd and I Johnstone (eds), The Oxford Handbook of International Organizations (Oxford University Press 2016) 470.

${ }^{67}$ B Jenkins, 'Now is Time to Revisit the Global Health Security Agenda' (7 March 2020) $<$ https://www.brookings.edu/blog/order-from-chaos/2020/03/27/now-is-the-time-to-revisit-theglobal-health-security-agenda/ $>$. $\quad{ }^{68}$ WHO (n 8) para 43. $\quad{ }^{69}$ WHO (n 9) Annex.

${ }^{70}$ On such instruments see WHO-WHE-CPI-2017.10 (2017) and WHO-WHE-CPI-2019.4 (2019). On data see WHO, 'Annual Report on the Implementation of the International Health Regulations (2005). Report by the Director-General' (12 May 2020) A73/14, para 11. Simulation exercises are interactive activities, carried out through table-top exercises or simulations of real events, that test the capability of a State to respond to a health emergency. An After Action Review is a qualitative review of actions taken by a State to respond to a concrete public health event as a means of identifying challenges and best practices related to the response phase.

71 See WHO, 'Protocol for Assessing National Surveillance and Response Capacities for the International Health Regulations in accordance with Annex 1 of the IHR. A Guide for Assessment Teams' (December 2010). 
presented to the 2016 World Health Assembly. ${ }^{72}$ The current version was further refined in 2018 based on suggestions by the WHO and external experts, taking account of early assessments carried out in a number of States. ${ }^{73}$

The JEE is grounded on a preliminary self-assessment by the State, followed by on-site visits and reviews by external experts focusing on 19 technical areas and is designed to evaluate a country's capacity to prevent, detect and respond by adopting a multi-sectoral national approach. The 19 technical areas, encompassing 49 indicators, largely overlap with the issues addressed in annual reports but are the subject of strict scrutiny, based on around 200 technical or contextual questions, supplemented by targets and parameters, and informed by documents provided in order to substantiate information. Still, doubts have been raised on the quality and accuracy of some proposed capacities and indicators, such as those concerning national legislation, policy and financing. ${ }^{74}$

The JEE mechanism is, furthermore, voluntary and based on a cooperative approach with the country concerned: for instance, the State's approval is required for the selection of experts and regarding the methodology to be adopted. It must also agree to the publication of findings and recommendations on the WHO website. Currently, 96 reports are publicly available, out of 112 on-site missions. ${ }^{75}$ Furthermore, the mechanism does not have an automatic impact on the reports produced by States, as significant differences exist — broadly evaluated at around 20 per cent - between the performance assessed in JEEs and the data provided by States in their reports. ${ }^{76}$ This phenomenon can largely be attributed to the tendency of the authorities involved to overestimate their performance, given that this is not subject to subsequent monitoring or assessment: this is especially marked in States with poor performance in indexes related to civil liberties and the rule of law, ${ }^{77}$ although a reduction in such divergences has recently been observed, partly attributed to a new reporting model having simplified the mechanism and permitting States to better assess the information required. ${ }^{78}$

It is thus clear that the external evaluation system, regardless of its positive impact, continues to suffer from shortcomings, particularly its deference to States as a result of its being based on self-assessment. The Covid-19 crisis will make it possible to test the efficiency of this evaluation tool in confronting an actual pandemic. Given the positive results of several assessments conducted through the JEE in recent years, it might be opportune to further reflect on the capacity of this instrument to properly monitor States' core capacities, even if the actual management of the pandemic by national authorities and their technical and political choices have played a critical role, since

72 On the interactions between GHSA and WHO initiatives see E Bell et al, 'Joint External Evaluation - Development and Scale-up of Global Multisectoral Health Capacity Evaluation Process' (2017) 23 Emerging Infectious Diseases (Supplement to December 2017) 33.

73 WHO, 'Joint External Evaluation Tool. Second Edition' (2018).

74 M Forzley, 'Global Health Security Agenda: Joint External Evaluation and Legislation. A 1Year Review’ (2017) 15 Health Security 312.

75 See data available <https://www.who.int/ihr/procedures/mission-reports/en/> and information provided in the 2020 report of the Director-General (n 70) para 11.

${ }^{76}$ F Tsai and R Katz, 'Measuring Global Health Security: Comparison of Self- and External Evaluations for IHR Core Capacity’ (2018) 16 Health Security 304.

77 F Tsai and B Turbat, 'Is Countries' Transparency Associated with Gaps between Countries' Self and External Evaluations for IHR Core Capacity?' (2020) 16 Globalization and Health 1.

78 N Kandel, 'Improvement in Annual Reporting of Self-Assessments to the International Health Regulations (2005)’ (24 May 2019) Weekly Epidemiological Record 1. 
States which have scored highly in JEE's assessments have still been severely impacted by the COVID-19 Pandemic. ${ }^{79}$

Support for the 'IHR Monitoring and Evaluation Framework' was nonetheless reiterated in the World Health Assembly Decision 71(15), which adopted the 'Fiveyear Global Strategic Plan to Improve Public Health Preparedness and Response, 2018-2023'.80 This document also reaffirms the provision of technical support by the WHO to States making use of such tools, as does the 2019 WHO Benchmarks for International Health Regulations Capacities, which also provide some indicators to assess actions carried out by States, such as the number of countries making use of the voluntary tools or having developed a National Action Plan for Health Security. Nonetheless, the final version of Decision 71(15) softened references to external review mechanisms: a sign of the continuing preference for self-assessment. ${ }^{81}$

The growing importance of these issues re-emerged in the resolution proposed in February 2020 by the Executive Board to the 73rd session of the World Health Assembly, concerning 'Strengthening preparedness for health emergencies: implementation of the International Health Regulations (2005)' ${ }^{82}$ This draft resolution was not particularly innovative, as it called for States to 'take actions to implement the unmet obligations' or to prioritise the improvement of health emergency preparedness, confirming their support for above-mentioned tools. However, the lack of specific targets, deadlines, and a desire to continue 'business as usual' in terms of the reporting procedure prompts doubts concerning the potential effectiveness of this resolution. Ironically, the Covid-19 crisis, which has dramatically tested States' preparedness, also resulted in the postponement of the debate on this resolution due to the 'virtual' character of the 73rd session of the World Health Assembly. ${ }^{83}$

\section{SOME IDEAS FOR REFORM}

While innovative in introducing obligations regarding certain structural measures, the 2005 IHR have faced a series of difficulties in guaranteeing the implementation of the core capacities required of States. Limits related to the IHR's legal architecture, such as the lack of legal clarity concerning the measures and thresholds to be implemented and its embryonic monitoring system, coupled with an institutional agenda that has

79 For instance, regarding the USA the JEE report scored all indicators as four or five out of five, except for a few exceptions dealing with surveillance systems for zoonotic diseases, radiation emergencies or communication engagement with affected communities. See WHO, 'JEE of IHR Core Capacities of the United States of America. Mission Report: June 2016' (2016) WHO/ WHE/CPI/2017.13.

${ }^{80}$ WHO, 'Implementation of the International Health Regulations (2005): Five-year Global Strategic Plan to Improve Public Health Preparednessand Response, 2018-2023' (26 May 2018) WHA71(15).

${ }^{81}$ GL Burci and J Quirin, 'Implementation of the International Health Regulations (2005): Recent Developments at the World Health Organization' ASIL Insight (25 September 2018) $<$ https://www.asil.org/insights/volume/22/issue/13/implementation-international-healthregulations-2005-recent-developments>.

82 WHO, 'Strengthening Preparedness for Health Emergencies; Implementation of International Health Regulations (IHR, 2005)’ (8 February 2020) EB146/CONF./17.

${ }^{83}$ For a preliminary assessment see P Villarreal, 'Pandemic Intrigue in Geneva: COVID-19 and the 73rd World Health Assembly' EJIL:Talk! (22 May 2020)<https://www.ejiltalk.org/pandemicintrigue-in-geneva-covid-19-and-the-73rd-world-health-assembly/>. 
not prioritised such issues, have meant that States have not been effectively pressed to fulfil their obligations. Other problems include the, largely under-emphasised, financial implications of such measures and the lack of domestic and international agendas prioritising future-oriented activities in the face of apparently more compelling issues. Even recent attempts within WHO to refocus attention on such issues, prompted by the continued non-performance of obligations, appear to have been too little and, unfortunately, too late.

The Covid-19 crisis, exacerbated by a lack of preparedness, should promote reforms, building on the political support expressed during the extraordinary G20 summit held in March 2020, where the WHO was asked to report in the coming months 'with a view to establish a global initiative on pandemic preparedness and response' ${ }^{84}$ Furthermore, within WHO a series of parallel initiatives have been launched to revise the existing system and propose potential reforms. Resolution 73.1 adopted in May 2020 by the World Health Assembly, ${ }^{85}$ requested the WHO Director-General to initiate an impartial evaluation to review the functioning of the IHR and the implementation of the relevant recommendations of previous IHR Review Committees, with a view to making recommendations to improve States' capacities. As a result, two bodies were set up: a) the 'Review Committee on the Functioning of the International Health Regulations (2005) during the COVID-19 Response' and; b) the 'Independent Panel for Pandemic Preparedness and Response'. ${ }^{86}$ Their reports and proposals, expected in 2021, will certainly address issues related to the core capacities included in the IHR. It is therefore timely to make some suggestions.

First, given the technical nature of the core capacities, it would be appropriate to provide them with more content than is currently the case, and moving away from their current approach of 'constructive ambiguity': Annex 1 currently reflects ' $[t]$ he widespread lack of clarity with respect to key State obligations in the current IHR' 87 which ultimately undermines compliance. Based on Article 55 IHR, and as was the case as regards Annex 7 in in 2014, ${ }^{88}$ Annex 1 could be formally amended by the World Health Assembly to better define the measures required, particularly through recourse to benchmarks and qualitative/quantitative standards.

Furthermore, an effective complementary role could be played by technical documents developed by WHO, as already envisaged in Article 13 IHR. These would both make it

${ }^{84}$ Extraordinary G20 Leaders' Summit, 'Statement on Covid-19' (26 March 2020) <https://g20. org/en/media/Documents/G20_Extraordinary\%20G20\%20Leaders\%E2\%80\%99\%20Summit_ Statement_EN\%20(3).pdf>.

85 See WHO, 'COVID-19 Response' (19 May 2020) WHA73.1, para 9(10).

86 See WHO, 'Update from the Co-Chairs of the Independent Panel for Pandemic Preparedness and Response' (21 September 2020) EBSS/5/3. For the early activities of the Review Committee see WHO, 'Report of the First Meeting of the Review Committee on the Functioning of the International Health Regulation (2005) during the COVID-19 Response' (8-9 September 2020) < https://www. who.int/publications/m/item/first-meeting-of-the-review-committee-on-the-functioning-of-theinternational-health-regulations-(2005)-during-the-covid-19-response $>$.

87 A Taylor et al, 'Solidarity in the Wake of COVID-19: Reimagining the International Health Regulations' (2020) 396 The Lancet 83.

88 WHO, 'Implementation of the International Health Regulations (2005)' (24 May 2014) WHA67 13. The text of the updated Annex 7 was included as Annex 5 to WHO, 'Sixty-Seventh World Health Assembly. Resolutions and Decisions' (2014) WHA67/2014/REC/1. Amendment to Annex 7 has changed the period of validity of international certificate of vaccination against yellow fever. 
possible to further operationalise Annex 1, providing it with more granular content, and might also permit an easy periodic review of standards and guidelines suggested to States for a proper compliance with core requirements, taking into account lessons learned from health emergencies and practice, thus rendering the IHR a living instrument. This would also facilitate a more consistent approach by the WHO than has been the case in the past. Additionally, the current Covid-19 crisis presents an opportunity to evaluate the 'IHR Monitoring and Evaluation Framework' and to see whether such tools are effective and able to provide concrete guidance on the review and implementation of core capacities.

Second, the monitoring system should permit effective scrutiny of compliance with the obligations related to core capacities, as the 'absence of any provision for such monitoring in the IHR hampers its effectiveness and relevance'. ${ }^{89}$ Indeed, the 2020 report of the Global Preparedness Monitoring Board has already advocated amending the IHR to include 'mechanisms for assessing IHR compliance and core capacity implementation, including a universal, periodic, objective and external review mechanism' ${ }^{90}$ The current Review Committee is also expected to review the 'implementation and reporting of IHR core capacities, including the possibility of establishing peer review processes for capacity assessments'. ${ }^{91}$

In this context, inspiration might be found in multiple approaches adopted in other areas of international law in order to develop compliance mechanisms which are less State-centric and provide more opportunity for challenge. For instance, independent technical experts could be involved in assessing States Reports, or civil society in the provision of information - which is already provided for by Article 9 IHR regarding the identification of events that may constitute a public health emergency of international concern. This opportunity might thus favour a more direct engagement of non-State actors in advocacy and monitoring activities related to global health instruments, as already occurred with the key role played by the Framework Convention Alliance for the 2003 convention on tobacco control. ${ }^{92}$

This might involve revision of the model used for State reports, based on the more detailed criteria provided by the JEE and the WHO Benchmarks. To avoid an excessive workload associated with annual reports and to encourage States to engage in more substantial analysis, the World Health Assembly might change the time frame for submitting mandatory reports, for instance fixing deadlines every $2-3$ years. This would imply the parallel development of a model for reports able to better assess existing core capacities, for instance with a more extensive use of quantitative/ qualitative benchmarks. Furthermore, self-assessments should be complemented by mandatory independent evaluations such as the JEE, to be carried out periodically (eg 4-5 years), and with links between the two. States unable to comply with the core capacities should be required to develop domestic implementation instruments, taking advantage of models such as the National Action Plan for Health Security to set proper milestones and a masterplan. It is odd that such plans were originally required under Articles 5 and 13 in order for States to obtain extensions to original deadlines regarding their compliance with measures required by such provisions, whilst noncompliant States are now no longer required to do so.

89 Taylor et al (n 87) 83.

90 Global Preparedness Monitoring Board, A World in Disorder (World Health Organization 2020) 43.

91 WHO, 'Report' (n 86) para 1.

92 Gostin (n 49) 217-18. 
Thirdly, financial and technical assistance can no longer be ignored, and is in the collective interest of States based on a rationale strategy, as developed States 'may foster the strengthening of health systems in other countries from a perspective of enlightened self-interest'. ${ }^{93}$ Past evaluations by the World Bank quantified the annual global investment in strengthening core capacities to be in the range of 1.9-3.4 billion dollars: a drop in the ocean compared to the losses prompted by Covid-19. ${ }^{94}$ However, many States do not have the capacity to implement such measures and the WHO is not equipped to support them. Although some programs have emerged in recent years, such as the World Bank's Pandemic Emergency Financing Facility, ${ }^{95}$ these have been insufficient. Similarly, past pledges made in certain diplomatic fora risk being little more than vacuous statements, such as those of G7 summits, where, regardless of States having 'committed to supporting 76 countries in building their IHR (2005) core capacities in four separate meetings, G7 Member States have not monitored the followup to these commitments', 96 and their effective implementation can obviously be doubted, particularly taking into account how G7 summits held in the aftermath of the Ebola pandemic 'did not explicitly commit funds nor agree to a concrete plan' ${ }^{97}$

Based on experiences related to other health issues such as the Global Fund to Fight AIDS, Tuberculosis and Malaria ${ }^{98}$, the GAVI Alliance or the Coalition for Epidemic Preparedness Innovation, public-private partnerships should be strengthened, channelling private funds toward this less appealing context. ${ }^{99}$ Assistance should, however, be subject to control mechanisms, anchored to the achievement of milestones concerning core capacities provided, for instance, in assessments related to the proposed national implementation plans or based on independent review mechanisms. Similarly, proposals have been made to request the International Monetary Fund to factor disease preparedness into analysis on country reports related to its so-called Article IV consultations in order to sharpen the economic incentive to devote sufficient domestic resources to pandemic preparedness. ${ }^{100}$

Fourthly, in order to further boost efforts, preparedness should be prioritised on international and national political agendas. Following the Ebola outbreak, the

93 Villarreal (n 20) 166-7.

94 Global Preparedness Monitoring Board (n 58) 31. On estimates of loss in the global gross domestic product of up to 5 per cent related to Covid-19 (roughly 5 trillion US Dollars) see World Bank, 'Global Economic Prospects' (June 2020) < https://www.worldbank.org/en/ publication/global-economic-prospects>.

95 P Osewe, 'Options for Financing Pandemic Preparedness' (2017) 95 Bulletin of the WHO 79; World Bank, 'From Panic and Neglect to Investing in Health Security: Financing Pandemic Preparedness at a National Level' (2017) <http://documents.worldbank.org/curated/en/ 979591495652724770/From-panic-and-neglect-to-investing-in-health-security-financingpandemic-preparedness-at-a-national-level>.

96 Global Preparedness Monitoring Board (n 58) 20.

97 S Moon et al, 'Will Ebola Change the Game? Ten Essential Reforms before the Next Pandemic. The Report of the Harvard-LSHTM Independent Panel on the Global Response to Ebola' (2015) 386 The Lancet, 2204, 2208.

98 On this experience see R Jürgen et al, 'The Global Fund to Fight AIDS, Tuberculosis and Malaria. Funding Basic Services and Meeting the Challenge of a Rights-Based Approach' in BM Meier and LO Gostin (eds), Human Rights in Global Health: Right-Based Governance for a Globalized World (Oxford University Press 2018) 421.

99 On such initiatives see GL Burci, and A Cassels (n 66) 450-1.

100 P Sand et al, 'Assessment of Economic Vulnerability to Infectious Disease Crisis' (2016) 388 The Lancet 2443. 
establishment by the UN General Assembly of a 'high level council on global public health crises' was recommended, ${ }^{101}$ a measure which was opposed by the IHR Review Committee because of the risk of duplicating fora and of a loss of leadership for WHO. ${ }^{102}$ As a result, only the informal Global Preparedness Monitoring Board composed of high-level independent members was established, whose ability to effectively represent an effective body to boost resources and mobilise political leaders and relevant stakeholders might be doubted. There is a need for more institutional and political support so that they can move beyond being seen as only of a technical health character.

This could be achieved, for instance, through periodic high-level political meetings within WHO or at the United Nations, generating a top-down effect and strengthening responses at the domestic level. It is to be hoped that the impetus provided in the recent extraordinary G20 meeting regarding the establishment of a global initiative on pandemic preparedness and response might generate some concrete and long-lasting results. This could finally lead to the development of initiatives aimed at pooling public and private funds internationally to support the provision of the financial and technical assistance required, particularly by less developed States, to establish sustainable and functional public health systems able to comply with the requirements imposed by the IHR for the common benefit of all States parties in a system which requires uniformity in approaches and common understandings.

Lastly, there is a need for cross-fertilisation from other sectors, rather than sectoral approaches.

For instance, paradigms pertaining to international disaster law could integrate preparedness measures related to the IHR within their broader frameworks, such as the Sendai Framework for Disaster Risk Reduction 2015-2030. ${ }^{103}$ This might also make it possible to tie into other elements of disaster risk reduction, such as domestic financing, the adequacy of the institutional and decision-making structures, or the management of information. ${ }^{104}$ Indeed, influenced by the current pandemic, the need to foster interactions between these two areas was recently stressed by UNGA Resolution 74/218, adopted on January 2020, which 'recognizes that biological hazards require strengthened coordination between disaster and health risk management systems'. ${ }^{105}$ However, despite having been included by the Sendai Framework among the risks to be assessed by States, ${ }^{106}$ biological risks are normally not yet fully integrated into national disaster risk reduction strategies. ${ }^{107}$

Human rights law may also be relevant. While the connection between human rights and the IHR has usually concerned restrictive measures adopted by States to cope with

101 UNGA, 'Protecting Humanity' (n 57) Recommendation 26.

102 WHO, 'Report' (n 56b) para $163 . \quad 103$ UNGA Res 69/283 (n 103) para 15.

104 On international legal implications for disaster risk reduction see K Samuel, M AronssonStorrier and K Bookmiller (eds), Disaster Risk Reduction and International Law (Cambridge University Press 2019).

105 UNGA Res 74/218 (23 January 2020) UN Doc A/RES/74/218, para 14.

106 UNGA Res 69/283 (n 83) para 15. As for an attempt to factor health concerns into disaster risk activities see also the 'Bangkok Principles for the implementation of the health aspects of the Sendai Framework for Disaster Risk Reduction 2015-2030' developed in $2016<\mathrm{https}$ :/www. preventionweb.net/files/47606_bangkokprinciplesfortheimplementati.pdf>.

107 M Toscano-Rivalta, 'Disaster Risk Reduction in Light of the COVID-19 Crisis. Policy and Legal Considerations’ (2020) 70 Questions of International Law 37. 
health emergencies, ${ }^{108}$ proposals have been made both to use core capacities to strengthen the content of relevant human rights obligations, such as Article 12 ICESCR, and to draw on models of human rights monitoring systems. ${ }^{109}$

This might be particularly appealing given the weakness of the dispute settlement mechanism provided by Article 56 IHR, concerning disputes relating to the interpretation or application of the IHR, ${ }^{110}$ which has caused some scholars to claim that 'the most stinging criticism of the IHR - and the one that exacerbates all other criticisms - is that an effective dispute resolution mechanism is absent from their provisions'. ${ }^{111}$ So far, none of the procedures provided for by Article 56 has been formally invoked, making it hard to see how it helps guarantee compliance with core capacities, a problem magnified by the non-confrontational and 'managerial'112 approach of the WHO to its relationship with States concerning the IHR. This is further compounded by 'the (non) existence of a statutory sanctioning mechanism in WHO's rules' ${ }^{113}$ in case of violations of the IHR, echoing the report of the Review Committee in relation to the H1N1 Pandemic where 'the lack of enforceable sanctions' was qualified as 'the most important structural shortcoming of the IHR'. ${ }^{114}$ As a result, recourse to mechanisms provided by instruments external to the IHR should be explored to incentivise compliance with obligations related to the core capacities.

Obviously, many of these proposals may prove ambitious and most require significant political, institutional and financial support. However, the crisis generated by Covid-19 demands that proper attention finally be dedicated to the implementation of the preparedness measures required by the IHR, as they constitute the (neglected) cornerstones of this system and, more relevantly, a global public good which is of universal concern. ${ }^{115}$

108 A Zidar, 'WHO International Health Regulations and Human Rights: From Allusions to Inclusion' (2015) 19 The International Journal of Human Rights 505.

109 B Toebes, 'States' Resilience to Future Health Emergencies: Connecting the Dots between Core Obligations and Core Capacities' ESIL Reflections (11 June 2020) <https://esil-sedi.eu/wpcontent/uploads/2020/06/ESIL-Reflection-Toebes-copy-1.pdf>.

110 Art 56 IHR maintains how in case of a dispute involving States they will enter into negotiations or any other peaceful means of their choice, with the possibility to involve the Director-General in case the dispute is not settled. A limited possibility to defer the case to an arbitration is provided in case of mutual consent. Furthermore, in the event of a dispute between WHO and one or more States parties the matter shall be submitted to the Health Assembly.

111 SJ Hoffman, 'Making the International Health Regulations Matter: Promoting Compliance through Effective Dispute Resolution' in S Rushton and J Youde (eds), Routledge Handbook on Global Health Security (Routledge 2014) 239, 240.

112 Alvarez (n 27) 225. In this regard this approach has been described as an attempt 'to remedy these capacity deficits by relying on "carrots" - such as clarifications of the law (like the Guidance document noted above) as accompanied by technical assistance to assist states' compliance' (ibid).

113 A Spagnolo, '(Non) Compliance with the International Health Regulations of the WHO from the Perspective of the Law of International Responsibility' (2017) 18 Global Jurist 1, 6.

114 WHO 'Report' (n 56a) 13.

115 D Gartner, 'Global Public Goods and Global Health' (2012) 23 Duke Journal of Comparative and International Law 303. 